\title{
Distribution and Molecular Characterization of Enteroaggregative Escherichia coli Isolated from Children in A Case-control Study of Acute Diarrhea in Thailand
}

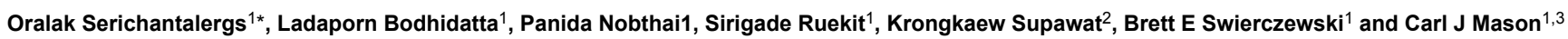 \\ ${ }^{1}$ Department of Enteric Diseases, Armed Forces Research Institute of Medial Sciences (AFRIMS), Bangkok, Thailand \\ ${ }^{2}$ Department of Medical Sciences, Ministry of Public Health, Bangkok, Thailand \\ ${ }^{3}$ Henry M. Jackson Foundation for the Advancement of Military Medicine, Bethesda, Maryland, USA
}

*Corresponding author: Oralak Serichantalergs, Department of Enteric Diseases, Armed Forces Research Institute of Medical Sciences, 315/6 Rajvithi Road, Bangkok 10400, Thailand, Tel: 662-696-2700; Fax: 662-644-4980, E-mail: oralaks@afrims.org

Received date: August 23, 2017; Accepted date: September 6, 2017; Published date: September 8, 2017

Copyright: (c) 2017 Serichantalergs O, et al. This is an open-access article distributed under the terms of the Creative Commons Attribution License, which permits unrestricted use, distribution, and reproduction in any medium, provided the original author and source are credited.

\begin{abstract}
Background: Enteroaggregative Escherichia coli (EAEC) is a major cause of acute diarrhea in children, adults, and travelers as well as an important cause of persistent diarrhea. Due to the limited information on EAEC virulence genes, EAEC isolates isolated from children with diarrhea and asymptomatic controls in Thailand were characterized for the presence of virulence factors.
\end{abstract}

Method: A study of diarrhea etiology in children from Thailand was conducted during 2008-2009 and 301 EAEC isolates were identified by pCVD432 probe/hybridization assays from diarrhea cases and controls. A total of 200 EAEC isolates were further characterized by PCR for EAEC genotypes, aggregative adherence fimbria (AAF/I-AAF/ IV), serine protease autotransporters of Enterobacteriaceae (SPATEs) class I \& II, and enterotoxin genes.

Results: The prevalence of EAEC isolates in this study were $7.7 \%$ and $9.1 \%$ among cases $(n=1803)$ and controls $(n=1790)$. Of 200 EAEC isolates, $69 \%$ of case and $58 \%$ of control isolates were classified as typical EAEC genotype. AAF/l (aggA) was the major fimbria type for cases $(37 \%)$ and controls $(23 \%)$, followed by AAF/III $(9 \%$, $13 \%), \operatorname{AAF} / I \mathrm{l}(11 \%, 17 \%)$ and AAF/IV $(5 \%, 3 \%)$. In confirmed cases, class II SPATE-sepA $(19 \%, 7 \%)$ and pic $(75 \%$, $60 \%)$ and enterotoxin-set $(75 \%, 61 \%)$ genes were detected in significantly more strains when compared to the controls. Additionally, typical EAEC isolates containing genes for AAF/I, Class II SPATEs (sepA, pic), and enterotoxin (set) were detected more frequently in cases than controls $(P$ value $<0.05)$.

Conclusion: This study suggests virulence gene heterogeneity of EAEC isolated from children with diarrhea as compared to asymptomatic controls, and that specific virulence genes are associated with diarrhea.

Keywords: Virulence genes; Aggregative adherence; Fimbria; SPATEs; Toxin; Diarrhea; Enteroaggregative E. coli; EAEC

\section{Introduction}

Enteroaggregative $E$. coli (EAEC) is a significant cause of acute gastroenteritis in both developing and industrialized countries [1-3]. EAEC is associated with traveler's diarrhea [4,5], endemic chronic pediatric diarrhea [6,7] and persistent diarrhea in immunocompromised patients $[8,9]$. EAEC is increasingly considered as an emerging enteric pathogen $[10,11]$. Among the diarrheagenic $E$. coli pathotypes, EAEC is more heterogeneous, with limited information on the roles and importance of specific virulence genes and putative gene products.

EAEC was originally defined by a phenotypic pattern described as aggregative adherence (AA) to HEp-2 cells [12]. Studies on the mechanisms involved in pathogenesis of EAEC suggested the presence of a variable package of co-inherited virulence genes carried on chromosomal islands and virulence plasmids [13]. Specific genes identified included a master transcriptional regulator (AggR) encoded on an EAEC virulence plasmid, pAA [14]. A cluster of aggR-activated genes (AAI) responsible for encoding type IV secretion was also found on a chromosomal island [15]. EAEC strains carrying multiple elements of the AggR regulon, and the genes encoding aat $\mathrm{A}$, aggR, and aaiC are considered "typical" EAEC, even though their pathogenicity potential remains unknown.

A cryptic DNA sequence termed 'CVD432' was 1) associated with aggregative adherence, 2) present on the plasmid pAA at locus aat, and 3 ) used as a molecular marker for EAEC in prior epidemiologic studies $[2,16]$. However, not all phenotypic EAEC strains are positive for CVD432, suggesting that additional virulence factors may be involved with pathogenesis [17].

The mechanisms of EAEC pathogenesis were reported as 1) adherence to the intestinal mucosa, 2) expression and release of enterotoxins and cytotoxins, and 3) subsequent host mucosal inflammation [18-20]. Adherence is mediated in part by aggregative adherence fimbriae (AAF) variants I-IV [21-25]. As many EAEC strains lack a known fimbria, other adherence mechanisms are likely present. EAEC toxins include serine protease autotransporters of the Enterobacteriaceae (SPATEs) $[26,27]$. The SPATEs pic and sepA were linked to EAEC pathogenesis $[28,29]$. Other toxins, to include Shigella 
Citation: Serichantalergs O, Bodhidatta L, Nobthai P, Ruekit S, Supawat K, et al. (2017) Distribution and Molecular Characterization of Enteroaggregative Escherichia coli Isolated from Children in A Case-control Study of Acute Diarrhea in Thailand. Clin Microbiol 6: 297. doi:10.4172/2327-5073.1000297

Page 2 of 6

enterotoxin (ShET1) and heat stable toxin (EAST-1), were also associated with EAEC diarrhea [30,31].

In Southeast Asia, EAEC is commonly isolated from stool specimens collected from both diarrhea cases and non-diarrhea controls, thus obscuring its contribution to diarrhea. This study determined the prevalence of EAEC and characterized EAEC isolates for adherence fimbria, enterotoxins, SPATE genes, and their significance to diarrhea cases and non-diarrhea controls from children in Thailand.

\section{Materials and Methods}

\section{Study site and EAEC isolation and identification}

A diarrheal surveillance study was conducted by the Department of Enteric Diseases, AFRIMS, Bangkok, Thailand and the Department of Medical Sciences, Ministry of Public Health, Thailand from 2008-2009 to identify diarrhea etiologic agents, including bacteria, parasites, and viruses, in children with and without diarrhea. The study was approved by the ethical review committee for Research in Human Subjects, Ministry of Public Health (MOPH), Nonthaburi, Thailand and the Walter Reed Army Institute of Research (WRAIR) IRB, Silver Spring, MD, USA . The study included 1803 children with diarrhea and 1790 non-diarrhea controls, enrolled with parental consent at different provincial hospitals throughout Thailand. At the time of study, stool samples were cultured to identify bacterial enteric pathogens (Salmonella spp., Shigella spp., Vibrio spp., Campylobacter spp., Aeromonas spp., Pleisiomonas spp., and E. coli) by standard microbiology techniques [32]. ELISA assays were used for the detection of rotavirus, adenovirus, and astrovirus (R-Biopharm AG, Darmstadt, Germany), and Giardia lamblia, Entamoeba histolytica and Cryptosporidium (ProspecT, Remel Products, Lexena, KS, USA) according to the manufacturer's instructions. Norovirus was detected by real-time PCR assay. Five lactose-fermenting and/or five nonlactose fermenting $E$. coli from each stool sample, identified on MacConkey agar plates, were spotted on a nylon membrane and processed for DNA hybridization using nonradioactive digoxigeninlabeled probe from pCVD432 [16] for the identification of EAEC. All $E$. coli isolates positive by CVD432 probe-hybridization assays were archived at $-70^{\circ} \mathrm{C}$ for further studies.

\section{EAEC isolates for characterization}

A total of 301 EAEC isolates were identified and archived from the diarrheal surveillance study described above. Two-hundred archived EAEC isolates, 100 from cases and 100 from controls, were selected for further molecular characterization. Of the 100 selected EAEC isolates from cases, 29 isolates were from stool samples where EAEC was detected as a single pathogen and 71 isolates were from co-infections. Of the 100 selected EAEC isolates from controls, 50 isolates were from stool samples where EAEC was detected as a single pathogen and 50 were from co-infections.

\section{Genomic DNA extraction of EAEC isolates}

Frozen EAEC isolates were freshly grown on Tryptic Soy Agar (TSA) plates. A suspension of bacteria in deionized water (molecular grade) was boiled at $100^{\circ} \mathrm{C}$ for $20 \mathrm{~min}$ and centrifuged at $10,000 \mathrm{rpm}$ for $10 \mathrm{~min}$., and the resulting supernatant was further used as DNA template for further studies.

\section{PCR assays for EAEC genotype, adherence fimbria and virulence genes}

For genotype identification, PCR using specific primers to confirm EAEC genotypes, a transcriptional activator gene (aggR), and chromosomal locus gene (aaiC) with DNA templates from selected EAEC isolates was conducted, as previously described [15]. For detection of EAEC aggregative adherence fimbria types, specific primers for the aggA, aafA, agg3A and agg4A genes were used to determine AAF fimbria type I to IV, respectively, as previously described [22,28,33]. For EAEC virulence-related genes, specific primers for Class I SPATEs genes (sat, sigA, and pet), Class II SPATEs genes (pic and sepA), and two enterotoxin genes (astA and set) genes were also included, as previously described $[22,28,33]$.

Multiplex PCR reaction was performed for detection of: 1) sepA, pic, and sigA 2) pic and pet; and 3) aaiC and astA, via three separate assays whereas singleplex PCR reactions were used to amplify and detect: 1) aggR 2) 4 fimbria genes agg A, aafA, agg $3 \mathrm{~A}$, and aag4A 3) the SPATE gene sat; 4) and the enterotoxin gene set in this study. Positive controls were EAEC type strains 17-2, EAEC 042, and Shigella flexneri 2457T. E. coli ATCC 11175 was used as a negative control. Resulting amplified products were analyzed by gel electrophoresis and ethidium bromide staining. A 2-Log DNA ladder and a 100bp-DNA ladder (New England BioLabs Inc., MA, USA and Gene Ruler., Thermo Fisher Scientific, MA, USA) were used as standard markers.

\section{Data analysis}

The frequency of each gene was calculated as numbers and percentages detected in EAEC isolates from cases and controls. The association of each gene with case or control status was tested for significant differences by Fisher's exact test-two tailed using GraphPad QuickCalcs Web site: http://www.graphpad.com/quickcalcs/ contingencyl.cfm (accessed February 2017). P values $\leq 0.05$ were considered statistically significance.

\section{Results}

\section{Identification and prevalence of EAEC isolates among cases and controls}

The prevalence of EAEC by the CVD432 probe-hybridization assay was 7.7\% (139/1803) and 9.1\% (162/1790) from cases and controls, respectively. EAEC was isolated both as a single pathogen and as part of a co-infection in stool from both cases and asymptomatic controls. Among EAEC isolates from cases, 20.9\% (29/139) were detected as a single pathogen and $79.1 \%(110 / 139)$ were isolated from stool samples with mixed infections (Table 1). In contrast, EAEC isolated from control stool samples as a single pathogen and mixed pathogens were roughly equal (cases: 50.6\%; controls: 49.4\%) respectively. EAEC was detected most often with rotavirus, Salmonella spp., Campylobacter spp., and norovirus in co-infections; however, EAEC among controls was detected most often with atypical enteropathogenic E. coli (only eae gene positive), Aeromonas spp., Salmonella spp. and Campylobacter spp. in co-infections. A total of 200 EAEC isolates, 100 from cases and 100 from controls, were selected for further molecular characterization.

\begin{tabular}{|l|l|l|l|}
\hline $\begin{array}{l}\text { Number of } \\
\text { samples }\end{array}$ & $\begin{array}{l}\text { Number of } \\
\text { EAEC } \\
\text { isolates }\end{array}$ & Number of EAEC isolates & $\begin{array}{l}\text { Number of EAEC } \\
\text { isolates characterized }\end{array}$ \\
\hline
\end{tabular}


Citation: Serichantalergs O, Bodhidatta L, Nobthai P, Ruekit S, Supawat K, et al. (2017) Distribution and Molecular Characterization of Enteroaggregative Escherichia coli Isolated from Children in A Case-control Study of Acute Diarrhea in Thailand. Clin Microbiol 6: 297. doi:10.4172/2327-5073.1000297

Page 3 of 6

\begin{tabular}{|l|l|l|l|l|l|}
\hline & $\begin{array}{l}\text { positive by } \\
\text { pCVD432 } \\
\text { probes (\%) }\end{array}$ & $\begin{array}{l}\text { Single } \\
\text { pathogen }\end{array}$ & $\begin{array}{l}\text { Mixed } \\
\text { pathogen }\end{array}$ & $\begin{array}{l}\text { Single } \\
\text { pathogen }\end{array}$ & $\begin{array}{l}\text { Mixed } \\
\text { pathogen }\end{array}$ \\
\hline $\begin{array}{l}\text { Cases } \\
(1803)\end{array}$ & $139(7.7)$ & 29 & 110 & 29 & 71 \\
\hline $\begin{array}{l}\text { Controls } \\
(1790)\end{array}$ & $162(9.1)$ & 82 & 80 & 50 & 50 \\
\hline
\end{tabular}

Table 1: Prevalence of EAEC isolated from stool of childhood diarrhea cases or asymptomatic controls in Thailand 2008-2009.

\section{Detection of EAEC genotypes}

Figure 1 depicts an ethidium bromide stained gel electrophoresis image of PCR generated amplicons from a series of multiplex PCR and singleplex PCR reactions, including positive controls for reference. Of the 200 EAEC isolates, the aatA, aggR, and aaiC triple combination genotype was the most commonly detected at $69 \%$ and $58 \%$ from cases and controls, respectively.

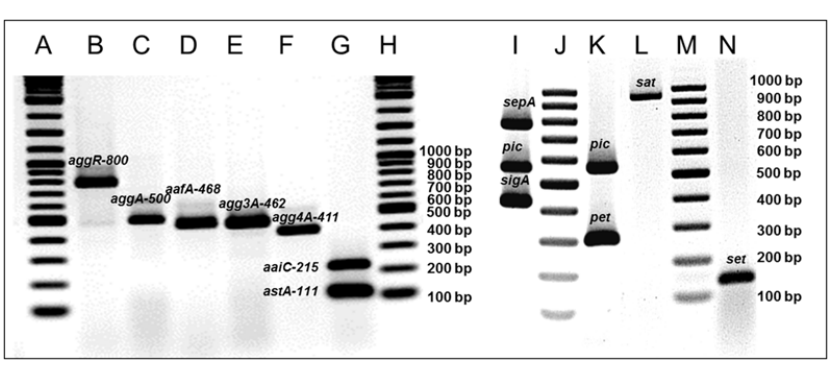

Figure 1: Gel electrophoresis of amplified gene products to identify EAEC virulence and fimbria genes. Lane $A$ and $\mathrm{H}$ : 2-Log DNA ladder- marker; Lane M: 100bp-DNA ladder-marker; Singleplex PCR reactions: Lane B: aggR; Lane C-F: Fimbria gene type I-IV (aggA, aafA, agg3A, and agg4A); Lane L: sat; and Lane N: set. Multiplex PCR reactions: Lane G: aaiC and astA; Lane I: sepA, pic, and sigA, Lane K: pic and pet.

The EAEC double genotype aat A, aaiC, and single genotypes aat $\mathrm{A}$ or aggR, were found less frequently. However, only $8 \%$ of the cases and $8 \%$ of the control EAEC isolates were positive for aatA. The EAEC genotype aat $\mathrm{A}$, aggR, was detected significantly more often in the controls $(26 \%)$ when compared to the cases $(12 \% ; \mathrm{P}=0.018)$, whereas the frequency of other EAEC genotypes were not significantly different (Table 2).

\section{Detection of adherence fimbria genes /types}

AggA, encoding for adherence fimbria gene type I (AAF/I), was detected in $37 \%$ and $23 \%$ of the cases and controls, respectively, and was the major fimbria type among all EAEC isolates $(\mathrm{P}=0.044$; Table 2). The aafA, agg $3 \mathrm{~A}$ and agg $4 \mathrm{~A}$ genes, encoding for AAF/II, AAF/III and AAF/IV respectively, were detected less commonly and did not show significant differences between EAEC isolates from cases and controls.

\section{Detection of enterotoxin and SPATEs genes}

Two enterotoxin genes, astA and set, encoding for heat-stable toxin (EAST-1) and Shigella enterotoxin respectively, were commonly

detected in EAEC isolates in this study (Table 2). There was no significant difference in the presence of ast $\mathrm{A}$ in cases and controls, and set was detected significantly more often in cases $(75 \%)$ as compared to the controls $(66 \% ; \mathrm{P}=0.048)$.

\begin{tabular}{|c|c|c|c|c|}
\hline \multirow[b]{2}{*}{ Genes } & \multirow[b]{2}{*}{ Target } & \multicolumn{3}{|c|}{ Prevalence of genes (\%) } \\
\hline & & $\begin{array}{l}\text { Cases } \\
(n=100)\end{array}$ & $\begin{array}{l}\text { Controls } \\
(n=100)\end{array}$ & $\begin{array}{l}\text { P value } \\
\text { (Fisher's } \\
\text { exact test, } \\
\text { two-sided) }\end{array}$ \\
\hline \multicolumn{5}{|l|}{$\begin{array}{l}\text { EAEC } \\
\text { genotype }\end{array}$} \\
\hline aatA & CVD432 positive & 8 & 8 & NS \\
\hline aat $A$, agg $R$ & $\begin{array}{l}\text { Transcriptional activators } \\
\text { gene encoded for the } \\
\text { expression of fimbria }\end{array}$ & 12 & 26 & 0.018 \\
\hline aatA, aaiC & Secreted protein & 11 & 8 & NS \\
\hline $\begin{array}{l}\text { aatA, aggR, } \\
\text { aaiC }\end{array}$ & Typical EAEC traits & 69 & 58 & NS \\
\hline \multicolumn{5}{|c|}{ Aggregative adherence fimbria } \\
\hline $\operatorname{agg} A$ & $\begin{array}{l}\text { Aggregative adherence } \\
\text { fimbria I (AAF/I) }\end{array}$ & 37 & 23 & 0.044 \\
\hline aafA & $\begin{array}{l}\text { Aggregative adherence } \\
\text { fimbria II (AAF/II) }\end{array}$ & 9 & 13 & NS \\
\hline $\operatorname{agg} 3 \mathrm{~A}$ & $\begin{array}{l}\text { Aggregative adherence } \\
\text { fimbria III (AAF/III) }\end{array}$ & 11 & 17 & NS \\
\hline $\operatorname{agg} 4 \mathrm{~A}$ & $\begin{array}{l}\text { Aggregative adherence } \\
\text { fimbria IV (AAF/IV) }\end{array}$ & 5 & 3 & NS \\
\hline \multicolumn{5}{|l|}{$\begin{array}{l}\text { Class } \\
\text { SPATE }\end{array}$} \\
\hline sat & $\begin{array}{l}\text { Secreted autotransporter } \\
\text { toxin }\end{array}$ & 30 & 28 & NS \\
\hline sigA & IgA protease-like homolog & 1 & 0 & NS \\
\hline pet & Plasmid-encoded toxin & 13 & 14 & NS \\
\hline \multicolumn{5}{|l|}{$\begin{array}{l}\text { Class } \\
\text { SPATE }\end{array}$} \\
\hline sepA & $\begin{array}{l}\text { Shigella extracellular } \\
\text { protease }\end{array}$ & 19 & 7 & 0.019 \\
\hline pic & Serine protease precursor & 75 & 60 & 0.034 \\
\hline \multicolumn{5}{|l|}{ Enterotoxin } \\
\hline astA & heat-stable toxin (EAST-1) & 28 & 33 & NS \\
\hline set & Shigella enterotoxin 1 & 75 & 61 & 0.048 \\
\hline
\end{tabular}

Table 2: Molecular characteristics of EAEC genotypes and virulence traits among 200 EAEC isolates, by cases and controls.

The Class I SPATE genes, sigA and pet, were detected less frequently than sat, and there was no significant difference in the presence of these genes in cases and controls (Table 2). The class II SPATE genes, sepA and pic, were detected in $19 \%$ and $75 \%$ from cases and $7 \%$ and 
Citation: Serichantalergs O, Bodhidatta L, Nobthai P, Ruekit S, Supawat K, et al. (2017) Distribution and Molecular Characterization of Enteroaggregative Escherichia coli Isolated from Children in A Case-control Study of Acute Diarrhea in Thailand. Clin Microbiol 6: 297. doi:10.4172/2327-5073.1000297

Page 4 of 6

$60 \%$ from controls, respectively. Both sepA and pic were detected more frequently and significantly in cases than controls $(\mathrm{P}=0.019$ and 0.034$)$.

\section{Association of adherence fimbria types, SPATEs and toxin genes among EAEC isolates}

Figure 2 depicts the association of adherence fimbria type I-IV, SPATEs, and enterotoxin genes of EAEC from cases and controls. EAEC of adherence fimbria type I (AAF/I) harbored pic and set in $86 \%$ and $65 \%$ of isolates from cases and controls, respectively.

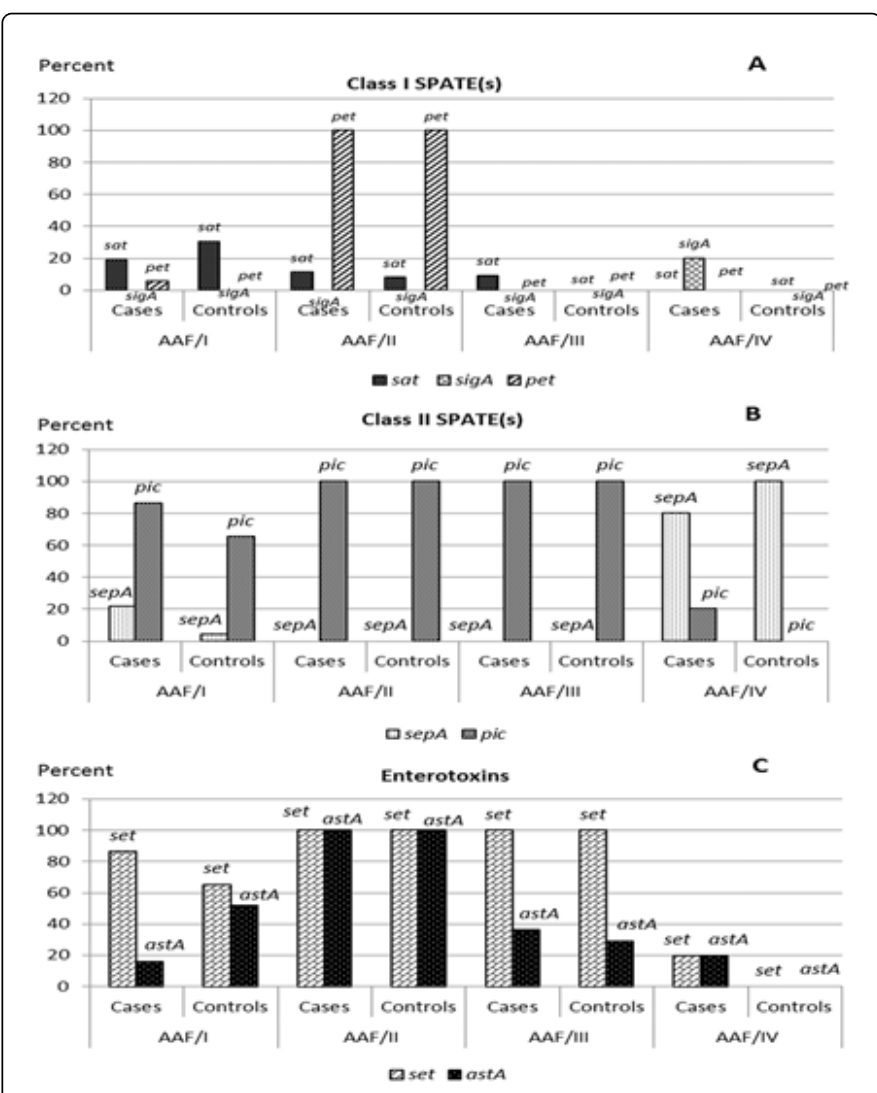

Figure 2: Bar graphs for association of virulence and fimbria genes among 200 EAEC isolates, by cases/controls. A: Percent of class I SPATE (sat, pet, and sigA) and fimbria types (AAF/I-IV) of 200 EAEC isolates, B: Percent of class II SPATE (pic and sepA) and fimbria types (AAF/I-IV) of 200 EAEC isolates, C: Percent of enterotoxins (set and astA) and fimbria types (AAF/I-IV) of 200 EAEC isolates.

In contrast, all EAEC isolates with fimbria type II (AAF/II) carried genes encoding for SPATEs (pet, pic) and enterotoxin (set, astA) in both cases and controls. All EAEC isolates with fimbria type III (AAF/ III) harbored genes encoding for pic and set in 100\% of isolates from cases and controls, but the SPATEs (sat, pet, and sepA) and enterotoxin (astA) genes were less prevalent in these isolates. Most EAEC isolates positive for adherence fimbria type IV (AAF/IV) possessed sepA $(80 \%$ and $100 \%$ of isolates from cases and controls, respectively), while $20 \%$ of these EAEC isolates from cases had genes encoding for the other SPATEs (sigA and pic) or enterotoxins (set and astA). None of the EAEC with fimbria type IV from controls carried class I SPATEs (sigA, pet and sat) and enterotoxins (set and astA).

\section{Association of fimbria types, SPATEs genes and enterotoxin genes among typical EAEC isolates in cases and controls}

Of the 200 EAEC isolates characterized under study, 69 isolates from cases and 58 from controls possessed typical EAEC traits. Typical EAEC isolates with fimbria type I (AAF/I) were detected more commonly in cases than controls $(47.8 \%$ and $27.6 \%$; $\mathrm{P}=0.027$; Table 3 ). Moreover, the typical EAEC-AAF/I isolates possessing either pic or set, or all three genes set, pic and sepA, were detected significantly more often in cases than controls, respectively $(\mathrm{P}=0.026,0.026$ and 0.038$)$. In contrast, typical EAEC with AAF/II was observed more often in controls than cases, and there was no significant association of typical EAEC genotypes with fimbria types AAF/II- IV.

\begin{tabular}{|l|l|l|l|}
\hline EAEC traits & $\begin{array}{l}\text { Cases } \\
(\mathbf{n = 6 9 )}\end{array}$ & $\begin{array}{l}\text { Controls } \\
(\mathbf{n = 5 8})\end{array}$ & $\begin{array}{l}\mathbf{P} \text { value (Fisher's exact } \\
\text { test, two-sided) }\end{array}$ \\
\hline Typical EAEC, AAF/I & 33 & 16 & 0.027 \\
\hline Typical EAEC, AAF/III & 9 & 12 & NS \\
\hline $\begin{array}{l}\text { Typical EAEC, } \\
\text { AAF/III }\end{array}$ & 11 & 17 & NS \\
\hline $\begin{array}{l}\text { Typical EAEC, } \\
\text { AAF/IV }\end{array}$ & 1 & 0 & NS \\
\hline $\begin{array}{l}\text { Typical EAEC, AAF/I, } \\
\text { sepA }\end{array}$ & 8 & 1 & 0.038 \\
\hline $\begin{array}{l}\text { Typical EAEC, AAF/I, } \\
\text { pic }\end{array}$ & 32 & 15 & 0.026 \\
\hline $\begin{array}{l}\text { Typical EAEC, AAF/I, } \\
\text { set }\end{array}$ & 32 & 15 & 0.026 \\
\hline $\begin{array}{l}\text { Typical EAEC, AAF/I, } \\
\text { sepA, pic, set }\end{array}$ & 8 & 1 & 0.038 \\
\hline NS: Not significant & & & \\
\hline
\end{tabular}

Table 3: Association of typical EAEC isolates, adherence fimbria types, and serine protease autotransporters of Enterobacteriaceae (SPATEs) genes, by cases and controls.

\section{Discussion}

There are limited data on the prevalence of EAEC genotypes and distribution of genes for adherence fimbria, enterotoxins, and SPATEs among EAEC isolates from Southeast Asia. This study reported the prevalence of these genes in 200 EAEC isolates collected from a casecontrol diarrhea surveillance study from young children in Thailand. All EAEC isolates in this study were positive for pCVD 432 and then further characterized for aggR and aaiC genotypes. The typical EAEC genotype (aat $\mathrm{A}$, aggR, aaiC) was the most prevalent EAEC genotype detected $(>50 \%)$. However, the frequency of the typical EAEC genotype was not significantly different between cases and controls.

Only 59\% (118/200) of EAEC isolates possessed genes for fimbria and we observed a varied distribution of fimbria types. The frequency of adherence fimbria type I-AAF/I (aggA) was the greatest among EAEC isolates from both cases and controls, followed by AAF/III (agg3A), AAF/II (aafA), and AAF/IV (agg4A). These findings were similar to other studies $[28,29]$ where nearly half of clinical EAEC isolates do not possess known major fimbria subunits. 
Citation: Serichantalergs O, Bodhidatta L, Nobthai P, Ruekit S, Supawat K, et al. (2017) Distribution and Molecular Characterization of Enteroaggregative Escherichia coli Isolated from Children in A Case-control Study of Acute Diarrhea in Thailand. Clin Microbiol 6: 297. doi:10.4172/2327-5073.1000297

Page 5 of 6

This study concluded that EAEC isolates harbored both class I \& II SPATE genes, but the proportion detected differed. Guyer et al. [34] reported that sat was associated with pathogenicity of uropathogenic E. coli and diffuse-adhering E. coli (DAEC). A previous study noted that sat was detected in $74.5 \%$ of clinical EAEC isolates from Denmark [28], while this effort observed sat in only $30 \%$ and $28 \%$ of EAEC isolates from cases and controls respectively.

SepA encodes for a major extracellular protein that promotes tissue invasion in $S$. flexneri [35]. Previous studies suggested that sepA is a valuable identification marker for virulent EAEC [18,29]. This study identified less distribution of sepA in EAEC isolates from Thailand compared to previous studies $[28,29]$. Therefore, the contribution of sepA to EAEC virulence should not be overlooked. Pic was related to a Shigella mucinase originally described in EAEC, $S$. flexneri 2 a, and uropathogenic $E$. coli, that mediates penetration and enhances host inflammatory responses $[18,26]$. Pic was significantly associated with EAEC infection as a single pathogen in prolonged diarrhea as compared to acute diarrhea in Peruvian children [36]. However, this study included only EAEC isolates with acute diarrhea, and as such, the association with prolonged diarrhea could not be confirmed. Although the prevalence of sepA was not as high as pic, this study reported a stronger association of sepA with EAEC isolates from diarrhea cases when compared to those bearing the pic gene. SetAB, encoding for Shigella enterotoxin ShET1, is located on a complementary strand of pic [27,33]. For this reason, both genes should be equally detected in EAEC isolates. Results from this study matched the predicted distribution of these two genes among characterized EAEC isolates.

Although there was no significant association of adherence fimbria types, SPATEs and enterotoxin genes in the 200 EAEC isolates from cases and controls in this study, there was an observed association of pet and sepA genes with EAEC isolates possessing AAF/II and AAF/IV fimbria, respectively, more commonly than with other fimbria types. This finding was similar to a previous study where the authors suggested co-transmission or functional linkage of pet and AAF/II [28]. Additionally, fimbria type $\mathrm{V}$ (AAF/V-agg5A) was recently reported in $12 \%$ of EAEC isolates from stool specimens of travelers in Denmark [37]; however, this study did not include PCR detection of this fimbria type.

More EAEC isolates were identified in asymptomatic controls than in cases in this study, and there was no significance association of typical EAEC isolates in samples where the organism was a monoinfection or co-infection (data not shown). This data strongly demonstrates that typical EAEC isolates, in combination with fimbria type I (AAF/I), SPATEs (sepA, pic) and enterotoxin (set) genes, were significantly associated more commonly with diarrhea cases than controls. As a result, the authors suggest that these genes are potential virulence markers for EAEC isolates, and that other host factors may serve an important role in EAEC pathogenesis. Future studies are warranted, particularly looking at the distribution of these genes in EAEC isolates in different geographic regions of the world.

\section{Declaration of Conflict of Interest}

Material has been reviewed by the Walter Reed Army Institute of Research. There is no objection to its presentation and/or publication. The opinions or assertions contained herein are the private views of the author, and are not to be construed as official, or as reflecting true views of the Department of the Army or the Department of Defense.
The investigators have adhered to the policies for protection of human subjects as prescribed in AR 70-25.

\section{Acknowledgment}

This study was financially supported by the Armed Forces Health Surveillance Branch- Global Emerging Infections Surveillance and Response Systems (AFHSB-GEIS), Silver Spring, MD, USA. We thank staff members of the Department of Enteric Diseases, AFRIMS for their excellent microbiology support. We also thank Umaporn Suksawad and Siriporn Sornsakrin for patient enrollment and sample collection.

\section{References}

1. Nataro JP, Steiner T, Guerrant RL (1998) Enteroaggregative Escherichia coli. Emerg Infect Dis 4: 251-261.

2. Okeke IN, Nataro JP ( 2001) Enteroaggregative Escherichia coli. Lancet Infect Dis 1: 304-313.

3. Pabst WL, Altwegg M, Kind C, Mirjanic S, Hardegger D, et al. (2003) Prevalence of enteroaggregative Escherichia coli among children with and without diarrhea in Switzerland. J Clin Microbiol 41: 2289-2293.

4. Adachi JA, Ericsson CD, Jiang ZD, DuPont MW, Pallegar SR, et al. (2002) Natural history of enteroaggregative and enterotoxigenic Escherichia coli infection among US travelers to Guadalajara, Mexico. J Infect Dis 185: 1681-1683.

5. Glandt M, Adachi JA, Mathewson JJ, Jiang ZD, DiCesare D, et al. (1999) Enteroaggregative Escherichia coli as a cause of traveler's diarrhea: clinical response to ciprofloxacin. Clin Infect Dis 29: 335-338.

6. Bhan MK, Bhandari N, Sazawal S, Clemens J, Raj P, et al. (1989) Descriptive epidemiology of persistent diarrhoea among young children in rural northern India. Bull World Health Organ 67: 281-288.

7. Fang GD, Lima AA, Martins CV, Nataro JP, Guerrant RL (1995) Etiology and epidemiology of persistent diarrhea in northeastern Brazil: a hospital-based, prospective, case-control study. J Pediatric Gastroenterol Nutr 21: 137-144.

8. Mossoro C, Glaziou P, Yassibanda S, Lan NT, Bekondi C, et al. (2002) Chronic diarrhea, hemorrhagic colitis, and hemolytic-uremic syndrome associated with HEp-2 adherent Escherichia coli in adults infected with human immunodeficiency virus in Bangui, Central African Republic. J Clin Microbiol 40: 3086-3088.

9. Wanke CA, Gerrior J, Blais V, Mayer H, Acheson D (1998) Successful treatment of diarrheal disease associated with enteroaggregative Escherichia coli in adults infected with human immunodeficiency virus. J Infect Dis 178: 1369-1372.

10. Huang DB, Okhuysen PC, Jiang ZD, DuPont HL (2004) Enteroaggregative Escherichia coli : an emerging enteric pathogen. Am J Gastrenterol 99: 383-389.

11. Kaur P, Chakraborti A, Asea A (2010) Enteroaggregative Escherichia coli : An Emerging Enteric Food Borne Pathogen. Interdiscip Perspect Infect Dis 2010: 254159.

12. Nataro JP, Maher KO, Mackie P, Kaper JB (1987) Characterization of plasmids encoding the adherence factor of enteropathogenic Escherichia coli. Infect Immun 55: 2370-2377.

13. Nataro JP, Baldini MM, Kaper JB, Black RE, Bravo N, et al. (1985) Detection of an adherence factor of enteropathogenic Escherichia coli with a DNA probe. J Infect Dis 152: 560-565.

14. Nataro JP, Yikang D, Yingkang D, Walker K (1994) AggR, a transcriptional activator of aggregative adherence fimbria I expression in enteroaggregative Escherichia coli. J Bacteriol 176: 4691-4699.

15. Dudley EG, Thomson NR, Parkhill J, Morin NP, Nataro JP (2006) Proteomic and microarray characterization of the AggR regulon identifies a pheU pathogenicity island in enteroaggregative Escherichia coli. Mol Microbiol 61: 1267-1282. 
Citation: Serichantalergs O, Bodhidatta L, Nobthai P, Ruekit S, Supawat K, et al. (2017) Distribution and Molecular Characterization of Enteroaggregative Escherichia coli Isolated from Children in A Case-control Study of Acute Diarrhea in Thailand. Clin Microbiol 6: 297. doi:10.4172/2327-5073.1000297

Page 6 of 6

16. Baudry B, Savarino SJ, Vial P, Kaper JB, Levine MM (1990) A sensitive and specific DNA probe to identify enteroaggregative Escherichia coli, a recently discovered diarrheal pathogen. J Infect Dis 161: 1249-1251.

17. Bouzari S, Jafari A, Azizi A, Oloomi M, Nataro JP (2001) Short report: characterization of enteroaggregative Escherichia coli isolates from Iranian children. Am J Trop Med Hyg 65: 13-14.

18. Boll EJ, McCormick BA (2012) A new understanding of enteroaggregative Escherichia coli as an inflammatory pathogen. Cell Adh Migr 6: 413-418.

19. Eslava C, Navarro-Garcia F, Czeczulin JR, Henderson IR, Cravioto A, et al. (1998) Pet, an autotransporter enterotoxin from enteroaggregative Escherichia coli. Infect Immun 66: 3155-3163.

20. Vila J, Vargas M, Henderson IR, Gascon J, Nataro JP (2000) Enteroaggregative Escherichia coli virulence factors in traveler's diarrhea strains. J Infect Dis 182: 1780-1783.

21. Bernier C, Gounon P, Le Bouguenec C (2002) Identification of an aggregative adhesion fimbria (AAF) type III-encoding operon in enteroaggregative Escherichia coli as a sensitive probe for detecting the AAF-encoding operon family. Infect Immun 70: 4302-4311.

22. Boisen N, Struve C, Scheutz F, Krogfelt KA, Nataro JP (2008) New adhesin of enteroaggregative Escherichia coli related to the Afa/Dr/AAF family. Infect Immun 76: 3281-3292.

23. Czeczulin JR, Balepur S, Hicks S, Phillips A, Hall R, et al. (1997) Aggregative adherence fimbria II, a second fimbrial antigen mediating aggregative adherence in enteroaggregative Escherichia coli. Infect Immun 65: 4135-4145.

24. Nataro JP, Deng Y, Maneval DR, German AL, Martin WC, et al. (1992) Aggregative adherence fimbriae I of enteroaggregative Escherichia coli mediate adherence to HEp-2 cells and hemagglutination of human erythrocytes. Infect Immun 60: 2297-2304.

25. Okeke IN, Lamikanra A, Czeczulin J, Dubovsky F, Kaper JB, et al. (2000) Heterogeneous virulence of enteroaggregative Escherichia coli strains isolated from children in Southwest Nigeria. J Infect Dis 181: 252-260.

26. Henderson IR, Czeczulin J, Eslava C, Noriega F, Nataro JP (1999) Characterization of pic, a secreted protease of Shigella flexneri and enteroaggregative Escherichia coli. Infect Immun 67: 5587-5596.
27. Henderson IR, Nataro JP (2001) Virulence functions of autotransporter proteins. Infect Immun 69: 1231-1243.

28. Boisen N, Ruiz-Perez F, Scheutz F, Krogfelt KA, Nataro JP (2009) Short report: high prevalence of serine protease autotransporter cytotoxins among strains of enteroaggregative Escherichia coli. Am J Trop Med Hyg 80: 294-301.

29. Boisen N, Scheutz F, Rasko DA, Redman JC, Persson S, et al. (2012) Genomic characterization of enteroaggregative Escherichia coli from children in Mali. J Infect Dis 205: 431-444.

30. Savarino SJ, Fasano A, Robertson DC, Levine MM (1991) Enteroaggregative Escherichia coli elaborate a heat-stable enterotoxin demonstrable in an in vitro rabbit intestinal model. J Clin Invest 87: 1450-1455.

31. Vila J, Gene A, Vargas M, Gascon J, Latorre C, et al. (1998) A case-control study of diarrhoea in children caused by Escherichia coli producing heatstable enterotoxin (EAST-1). J Med Microbiol 47: 889-891.

32. Isenberg HD (2004) Clinical microbiology procedures handbook, 2nd ed. Washington DC: ASM Press.

33. Behrens M, Sheikh J, Nataro JP (2002) Regulation of the overlapping $\mathrm{pic} / \mathrm{set}$ locus in Shigella flexneri and enteroaggregative Escherichia coli. Infect Immun 70: 2915-2925.

34. Guyer DM, Henderson IR, Nataro JP, Mobley HL (2000) Identification of sat, an autotransporter toxin produced by uropathogenic Escherichia coli. Mol Microbiol 38: 53-66.

35. Benjelloun-Touimi Z, Sansonetti PJ, Parsot C (1995) SepA, the major extracellular protein of Shigella flexneri: autonomous secretion and involvement in tissue invasion. Mol Microbiol 17: 123-135.

36. Durand D, Contreras CA, Mosquito S, Ruiz J, Cleary TG, et al. (2016) pic gene of enteroaggregative Escherichia coli and its association with diarrhea in Peruvian children. Pathog Dis 74.

37. Jonsson R, Struve C, Boisen N, Mateiu RV, Santiago AE, et al. (2015) Novel aggregative adherence fimbria variant of enteroaggregative Escherichia coli. Infect Immun 83: 1396-1405. 